rev.relac.int.estrateg.segur.9(1):157-177,2014

\title{
TRAUMATISMO E IDENTIDADES ESTIGMATIZADAS: MIGRACIONES FORZADAS POR CONFLICTOS BÉLICOS•
}

\author{
Eliana Cárdenas Méndez** \\ "El enemigo no es destruido en la batalla. \\ Le ganas destruyendo su mente, su inteligencia y su esperanza". \\ Poster militar en el Petén ${ }^{1}$
}

\section{RESUMEN}

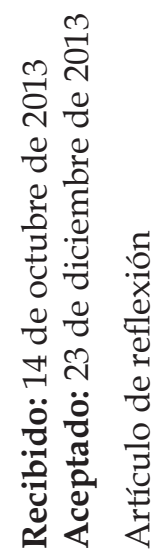

En la línea de las subjetividades, la migración es un evento que transforma la vida de las personas, debido a las causas que motivaron el desplazamiento, periplo de los traslados e inserción en las comunidades receptoras. Este proceso es mucho más aleccionador en el caso de las migraciones forzadas por conflictos bélicos, porque se trata de una fase que reconoce la violencia como eje rector del desplazamiento, que tiene repercusiones no solo en

* Este artículo es la evolución del trabajo "Esos históricos infatigables, dinámicas migratorias de guatemaltecos en el Estado de Quintana Roo". financiado por CONACYT.

** PhD. Profesora investigadora, Universidad de Quintana Roo. elianacardenas@hotmail.com

1. http://www.gam.org.gt/files/public/books/MASACRESenGUATEMALA.pdf 
aquellos que vivieron las experiencias del conflicto armado, sino sobre los diagramas vitales de las generaciones posteriores.

Este trabajo propone estudiar el trauma como una categoría clave para el estudio de las migraciones forzadas por conflictos bélicos, tomando como referencia el éxodo de los indígenas mayas del norte de Guatemala, en el contexto de la lucha contrainsurgente, en la década de los 80 del siglo XX. El traumatismo, en tanto evento disruptivo, es una secuela inherente a las migraciones forzadas en contextos de violencia, que se revela como despojo subjetivo e invalidez política de individuos y colectivos.

Palabras clave: Migraciones forzadas, traumatismo, identidades estigmatizadas.

"The enemy is not destroyed in the battle. You win by destroying his mind, his intelligence and his hopes". Military poster in El Peten

\title{
TRAUMA AND STIGMATIZED IDENTITIES: FORCED MIGRATIONS DUE TO ARMED CONFLICTS
}

\begin{abstract}
In the line of subjectivities, migration is an event that alters the life of people, for reason of the causes that caused the displacement, the actual journeys and the incorporation in the receiving communities. This process is even clearer in the case of migrations forced by armed conflicts, because it is a way that recognizes violence as the guiding force of the displacement, which not only affects those who lived the experience of armed conflicts, but also the vital diagrams of following generations.

This article proposes to study trauma as a key category for the learning about migrations forced by armed conflicts, taking as reference the exodus of the Mayas from the north of Guatemala, during the counter-insurgency struggles in the 80s of the 20th century. Trauma, among all disruptive events, is an inherent sequel to forced migrations in the presence of violence, that reveals itself as a plunder of subjectivity and political disability of individuals and groups.
\end{abstract}

Keywords: Forced migrations, traumatism, stigmatized identities. 
"O inimigo não é destruído na batalha. Ganha-se dele, destruindo sua mente, sua inteligência e sua esperança" Poster militar em Petén

\section{TRAUMATISMOS E IDENTIDADES ESTIGMATIZADAS: MIGRAÇÕES FORÇADAS POR CONFLITOS BÉLICOS}

\section{RESUMO}

Na linha das subjetividades, a migração é um evento que transforma a vida das pessoas devido às causas que as levaram ao deslocamento, périplo das transferências e inserção nas comunidades acolhedoras. Este processo é muito mais instrutivo no caso das migrações forçadas por conflitos bélicos, porque se trata de uma fase que reconhece a violência como o eixo orientador do deslocamento, que tem implicações não só para aqueles que viveram as experiências do conflito armado, mas também sobre os diagramas vitais das gerações posteriores.

O propósito deste trabalho é estudar o trauma como uma categoria fundamental para a análise das migrações forçadas pela guerra e tem como referência o êxodo dos índios Maias do norte da Guatemala, no contexto de luta da contra-insurgência na década de 80 do século XX. O traumatismo, como um evento perturbador, é uma sequela inerente às migrações forçadas em contextos de violência, que se revela como desapropriação subjetiva e incapacidade política de indivíduos e coletivos.

Palavras-chave: migração forçada, trauma, identidades estigmatizadas.

\section{INTRODUCCIÓN}

\section{Esa inmensidad salada}

Habíamos emprendido el viaje temprano a la mañana, rumbo a la ciudad de Chetumal, para concretar la reiterada y vieja invitación que les había hecho a comer mi casa. El entusiasmo de mis invitados me hizo imaginar que reanudaríamos las largas conversaciones durante el viaje, pero sucumbieron al calor y la humedad y cayeron en un sueño profundo. Al llegar decidí pasearlos un poco por el Boulevard antes del arribo a mi domicilio. Dormían plácidos en el asiento trasero del carro. Hablé fuerte para anunciarles que habíamos llegado, pero estaban tan profundos que debí tocarlos y mecerlos un poco. Despertaron sonrientes y de prisa se apearon del coche, pero al instante se quedaron petrificados frente al espectáculo del mar, en la bahía de Chetumal. Ese domingo a las dos de la tarde, aunque el cielo movilizaba a los lejos espesos nubarrones, el mar se agitaba suavemente en un remolino de verdes-azulados; las breves olas de la bahía se 
dejaban arrastrar por la brisa hasta la orilla y se desmayaban entre los manglares. Los invité a acercarnos para tocar el agua, pero ellos no se movían. Abrían y cerraban los ojos y después los abrieron inmensamente. En algún momento sentí que me pedirían refuerzo para poder capturar esa inmensidad salada, para no perderla de la vista; era todo un espectáculo: No se sabía quién miraba a quién. Esperé conmovida hasta que vi cómo recuperaban la risa y cómo la cara se les iba llenando de una felicidad en borbotones; me siguieron con prudencia, después se detuvieron en ese punto donde la brisa trae gotas de mar y lo llena todo de un rocío salobre; allí empezaron a mover la cabeza, y la risa se hizo grande en sus bocas hasta que estalló en carcajadas. Me di cuenta enseguida que nunca habían visto el mar. "Nunca habíamos visto el mar, nunca habíamos llegado hasta aquí". Con esta declaración se anticiparon a mi pregunta.

Esperé. Ellos siguieron riendo embelesados unos instantes más hasta que él se animó: puso la mano sobre su frente a manera de visor, intentando hurgar el horizonte. Pero fue ella la que apartando la mirada de ese festín de colores y apuntando con el dedo hacia la inmensidad me preguntó: "¿el mar termina donde se ve la raya larga?" Ante el estupor que me produjo la interpelación, ensayé varias respuestas mentalmente, tratando de tender un puente entre estas dos abismales representaciones del mundo, la de ellos y la mía. Vencida por la imposibilidad, respondí, con un dejo de resignación: Sí, en esa raya larga termina el mar².

El fragmento con el que inicia este texto refiere la experiencia del descubrimiento del mar, por parte de una pareja de exrefugiados guatemaltecos, un matrimonio de la etnia maya, hablantes de la lengua Mam, pertenecen a la primera generación del conflicto armado que llegó a Chiapas, México en 1982. Don Florencio y doña Teodora viven en Mayabalam, una de las comunidades que se formaron junto con Isidro La Laguna y Kuchumatan, a raíz de la reubicación de los refugiados en Quintana Roo. Son campesinos, ella cría animales de patio y se ocupa de las labores domésticas. Él se dedica a las labores del campo y atiende un pequeño negocio donde vende artículos de mercería y papelería.

La historia en sí no tendría nada de particular sino fuera porque desde hace veinticuatro años los habitantes de las comunidades de Mayabalam vienen diariamente al mercado Lázaro Cárdenas, en la Ciudad de Chetumal, a vender los frutos de su trabajo como campesinos. Al mismo tiempo es el lugar a donde vienen a abastecerse de productos que no producen y que revenden en pequeños comercios en sus localidades. El boulevard Bahía se encuentra del mercado a 15 minutos caminando, bajo el intenso calor del medio día y, sin embargo, los visitantes diarios e itinerantes procedentes de esta comunidad no conocen el mar. Todos tienen una relación con el espacio absolutamente tangencial, bajan del autobús y realizan

2. Doña Teodora y don Florencio, hablantes de Mam, de la comunidad de Mayabalam. Chetumal, Quintana Roo, Verano del 2009. 
sus labores comerciales en el mercado; y se abastecen en un perímetro aproximado de un kilómetro y medio a la redonda. La circulación por un ámbito tan restringido dentro del espacio urbano habla de una especie de autoconfinamiento, una conducta que responde en gran medida a una identidad estigmatizada. La presencia de los pueblos indígenas en la ciudad tiene varias implicaciones, tanto en la conceptualización del espacio, como en términos culturales; su presencia en la ciudad cambia la forma de autopercibirse y la forma de percibir a los demás; así, a medida que el escenario de interacción se vuelve más complejo, el proceso de negociación de la identidad también lo hace. El discurrir por la ciudad de manera tangencial y anónima es haber optado por el enmascaramiento para no explicar, evitar el descrédito o el rechazo social. Por otro lado, la ciudad, en este caso concebida solamente como un espacio de negociación comercial, reduce la expansión del diámetro de movilidad que implica también retos y negociaciones identitarias a las que, en gran medida, han claudicado (Turqui, 2006:55).

El autoconfinamiento es, entre otras, una de las secuelas que deja el trauma de la migración forzada por conflictos bélicos; es indicador de una violencia internalizada que tiene su origen en una identidad estigmatizada, agudizada por el conflicto armado, que desembocó en la migración forzada de las comunidades del norte de Guatemala en los años 80 del siglo pasado.

Es frecuente presentar la migración, desde la perspectiva de las subjetividades, como un evento que transforma, independientemente del balance, la vida de las personas o comunidades. Sin embargo, es un hecho que las migraciones forzadas por conflictos bélicos tienen el componente de traumatismo, en el sentido de un evento disruptivo que transfigura radicalmente la vida de todos aquellos que han debido experienciar el hecho. Las migraciones forzadas por conflictos bélicos no son un evento en sí mismo, sino un resultado, un desenlace al que le antecede una serie de episodios que progresivamente instalan la incertidumbre y desmontan el andamiaje de certezas básicas en las cuales se orienta el sentido vital de las personas.

La dimensión del traumatismo, en el estudio de las migraciones forzadas por conflictos bélicos, no solo revela la pertinencia de la transdisciplinariedad en el análisis de fenómenos sociales en general, sino que permite vincular los surcos de la memoria, individual y/o de grupo étnico en este caso, con entramados históricos estructurales; de esta manera los episodios recuperan su contextualización en tiempo y espacio y con ello es posible la recuperación de los refugiados como sujetos históricos y agentes de cambio.

El objetivo de este trabajo es presentar, en la línea del discurso del traumatismo o el sufrimiento social, algunas de las formas en las que se manifiesta y vive el despojo subjetivo, así como la invalidez política entre los ex refugiados guatemaltecos de las comunidades del Mayabalam, que vivieron la experiencia de la migración forzada por el conflicto armado en Guatemala y la repercusión de este desenlace en la generación posterior, en los hijos de los indígenas exrefugiados guatemaltecos. 


\section{CONSIDERACIONES HISTÓRICAS}

A todo lo largo del siglo XX la región latinoamericana fue escenario, en su condición de comunidad receptora, de movilizaciones de población por motivos políticos de los migrantes que huían de la Primera y Segunda Guerra Mundial y la Guerra civil española; posteriormente, desde la segunda mitad del siglo XX, y a raíz de diversos conflictos políticos protagonizados en los diferentes Estados nacionales, origen de grandes movilizaciones, tanto al interior de los territorios nacionales, y otros que implicaron cruce de fronteras internacionales. Las feroces dictaduras, en los años 70 en el Cono Sur, provocaron importantes dinámicas de población hacia otros países de América Latina, Europa y los Estados Unidos. La región centroamericana, por su parte, vivió importantes movilizaciones internacionales en el marco de la llamada Guerra sucia, en países como El Salvador, Nicaragua y Guatemala. Sin embargo, ninguna fue tan dramática en su condición de vulnerabilidad como la que vivieron los disímiles grupos étnicos del Ixkán, en el norte de Guatemala, debido a que debieron abandonar sus tierras por el diseño político del programa contrainsurgente del Estado guatemalteco, entre los que destaca la persecución hacia cualquier reivindicación o expresión de intereses populares; en el marco de este proyecto de contrainsurgencia, el Estado convirtió en objetivo militar a estas poblaciones, acusándolos de servir de base social a la guerrilla (Cárdenas, 2011:28).

Es conocido por todos que el fenómeno en cuestión no culminó con el exilio de un millón de guatemaltecos y el arribo de cuarenta mil de refugiados al Estado de Chiapas en México, sino que debieron experimentar también una reubicación forzada a los Estados de Campeche y Quintana Roo; cabe mencionar que esta decisión, por parte del ejecutivo federal, tenía dos objetivos principales, según se argumentó oficialmente: proteger a los refugiados de las incursiones y ataques del Ejército guatemalteco en el Estado de Chiapas ${ }^{3}$ y evitar un conflicto bilateral debido al desbordamiento del conflicto armado de Guatemala hacia el territorio nacional. A partir de allí, hemos reconocido varios movimientos de población: 1) La migración de retorno. 2) El retorno a México de los retornados. 3) Diversas dinámicas al interior del

3. Véase http://www.gam.org.gt/files/public/books/MASACRESenGUATEMALA.pdf Según este informe En diferentes ocasiones el Ejército guatemalteco perpetró ataques contra los refugiados en el Estado de Chiapas: El 30 de enero de 1982 en las Hamacas, La Trinitaria (5 ejecutados). El 8 de febrero de 1982 en Chajul, Chiapas (17 muertos por una granada). El 12 de septiembre de 1982 en San Pedro, Chiapas (6 ejecutados). En octubre de 1982 en Rancho Teja, Comala, Chiapas (11 ejecutados. En marzo de 1983 en Las Hamacas (5 ejecutados). En 1983, sin fecha específica en Matzán, Chiapas (sin número específico de decesos). El 30 de abril de 1983 en El Chupadero (9 ejecutados, un niño fue ejecutado después de haberlo castrado y posteriormente lo azotaron contra una pared; a una mujer embarazada le sacaron el feto). El Chupadero en 1984 (3 desaparecidos). El Chupadero, Chiapas, en 1984 (sin fecha precisa; sin número específico de decesos). En 1985, en La Hamaca (sin fecha precisa; sin número específico de decesos). Es importante señalar que después de la incursión de los kaibiles, grupo de élite del Ejército guatemalteco, al Chupadero, Chiapas, el 30 de abril de 1983, y debido a la crudeza de los acontecimientos, el gobierno mexicano toma la decisión de reubicar a los refugiados. 
Estado de Quintana Roo, principalmente a los polos turísticos de Cancún y Playa del Carmen, así como a Chetumal, la capital del Estado quintanarroense. 4) Hacia la Unión americana (Cárdenas, 2011:32).

Este trabajo es evolución de un trabajo anterior ${ }^{4}$, algunos de cuyos esfuerzos están orientados en posicionar críticamente el concepto de migraciones forzadas por conflictos bélicos, con estatuto analítico propio, diferenciable de otras dinámicas de población involuntarias; aparte de ofrecer una definición instrumental, llama la atención no solo a las causas que, a mi juicio, responden siempre a contextos histórico, políticos y económicos, sino que advierte sobre efectos y la resonancia que tiene sobre comunidades y personas la experiencia de la migración forzada; estos efectos aluden a aspectos subjetivos-biográficos que a su vez tienen un impacto en las dimensiones históricas, políticas y sociales. El traumatismo, en el sentido de herida, de marca, pero también como evento disruptivo, es un elemento inherente a las migraciones forzadas por conflictos bélicos y se revela como despojos subjetivo e invalidez política.

\section{DECLARACIÓN DE PRINCIPIOS}

¿Por qué insistir en posicionar conceptualmente el tema de las migraciones forzadas? Las migraciones forzadas son hechos históricos y tienen su contrapartida analítica en el campo de las ciencias sociales; sin embargo, la necesidad de entrar en tales rescoldos obedece al posicionamiento político de la comunidad internacional que, a través de diferentes categorías jurídicas, encubre las causas de las migraciones y, de hecho, el estatus de migrante propiamente; responde, por otro lado, a contextos académicos particulares, donde el tema migratorio es punta de lanza y ha generado importantes contribuciones académicas sobre migración indígena maya a los polos turísticos de Cancún y Playa del Carmen, migraciones internas en la Península de Yucatán o ha vinculado temáticas como la migración y el turismo. En este contexto, hablar de migraciones forzadas no es tan obvio. A la sazón, diferentes investigadores han planteado la necesidad de distinguir entre movilidades poblacionales y migración propiamente bajo el siguiente silogismo: Todas las migraciones implican movimientos de población, pero no todos los movimientos de población pueden circunscribirse bajo el concepto de migración. Aunque el señalamiento es irrefutable, la cuestión es que sirve de paso para negar a las movilizaciones de población por conflictos bélicos el estatus de migración.

En otras ocasiones he insistido que en estas posturas el concepto de migración está fuertemente condicionado por los diferentes paradigmas economicistas y he hecho hincapié en que esta

4. Cárdenas Méndez, Eliana (2011). Esos históricos infatigables: Dinámicas migratorias de guatemaltecos en el estado de Quintana Roo 1984-2009, Plaza y Valdés, México; A este libro voy a referirme reiteradamente en este ensayo por razones expositivas y en parte porque persigo como objetivo esclarecer algunas ideas que en aquel trabajo quedaron en el tintero. 
perspectiva ensombrece la multiplicidad de aristas, condicionantes, determinantes y las variantes que tiene el fenómeno. La migración, para ser reconocida como tal, requiere en este contexto académico ${ }^{5}$ un tiempo, una distancia e inserción social y económica en la comunidad receptora. Y lo son ciertamente para el caso de las migraciones económicas, pero los móviles económicos no son las únicas razones por las cuales las personas migran y en modo alguno son estas las únicas que pueden considerarse como migración.

Uno de los efectos de esta perspectiva es el limbo conceptual en el que se halla confinada la migración forzada, al punto que se le ha desalojado del concepto mismo de migrantes a aquellos que han debido abandonar sus territorios y han sido obligados a un peregrinar por diferentes países buscando asilo, con argumentos que pueden resumirse de la siguiente manera: a) Los exiliados no tienen en el momento de la salida un proyecto de vida en el lugar de albergue. b) Tienen un estatus diferente a los de cualquier otro que migrante y son abrigados por la ACNUR. c) No son voluntarias. d) El exiliado, al ser reconocido como refugiado, recibe apoyo de la ACNUR y, por lo tanto, no se inserta laboralmente en la comunidad de recepción. d) Los migrantes forzados tienen como horizonte el retorno y no buscan la residencia en la comunidad receptora. Cada uno de estos incisos, presentados para cuestionar la validez del concepto de migraciones forzadas, no solo revela su desmentido en la historia de las migraciones forzadas, sino que genera la confusión entre un estatus jurídico como el de refugiado e inmigrante; ignora que el estatus migratorio y el de refugiado, particularmente, es una forma de control de los Estados para regular las migraciones indeseadas, aquellas motivadas por causas políticas y/o con ocasión de un conflicto armado $^{6}$; adicionalmente, las arroja también del plano analítico y las conmina a una suerte de exilio conceptual e invisibiliza, quizá una de las formas más recurrentes de las dinámicas de población en la actualidad.

El asunto se hace más complejo si tenemos en cuenta que las migraciones forzadas se definen por oposición a las migraciones voluntarias, porque lo cierto es que un migrante forzado puede ser aquel que debe abandonar su espacio por agentes y determinantes externos como los planes de desarrollo o infraestructura (carreteras, puentes, sistemas de transportes etc.), fenómenos naturales (huracanes, tornados, desbordamientos de ríos, deslaves, etc.), pruebas de experimentación nuclear, y se incluyen recientemente a los migrantes económicos, debido a que es tal la precariedad en la que viven que las personas no tienen en realidad ningún margen de elección y se ven forzados a abandonar el territorio, y se incluye en las modalidad de migrantes forzados a aquellos que huyen por motivos políticos o por conflictos bélicos.

5. En el seminario permanente de migraciones de la Universidad de Quintana Roo, el tema se actualiza reiteradamente desde el año 2008, año en el que fue creado, y aún no se encuentra un terreno analítico sosegado.

6. Para una aproximación sucinta véase: Posada, Paola Andrea (2009) "Refugiados y desplazados forzados. Categorías de la migración forzada creadas como medidas de contención de las migraciones no deseadas" Revista de estudios políticos, Medellín, julio-diciembre de 2009 pp. 131, 152 
Ante esa especie de dispersión conceptual, y al reconocimiento de que todas las anteriores formas de movilidad humana incluyen una serie de factores externos que prescriben la decisión, de forma inexorable, la decisión de las personas, he propuesto que las migraciones forzadas deben tener un apellido; que no se puede hablar de migraciones forzadas, en términos genéricos, sino que es preciso indicar la estirpe. En este sentido he propuesto definir las migraciones forzadas por conflictos bélicos como aquellos movimientos de población provocados por acciones humanas que ponen en peligro de manera inexorable la vida de otras personas y, por tanto, están vinculadas con graves abusos a los derechos humanos. Las migraciones forzadas por conflictos bélicos son provocadas por la acción violenta y mortal de unos seres humanos sobre otros, realizadas al amparo del poder, la legalidad y la institucionalidad; son involuntarias y producidas por temor ante una situación de conflicto armado, que amenaza de forma perentoria la vida, la integridad física y la libertad de las personas; son masivas e implican el cruce de fronteras internacionales.

Las migraciones forzadas, en este sentido, deben definirse no solo por las determinantes causales, sino por los efectos que produce en los diagramas vitales, porque se trata de un evento traumático, en el sentido de un evento disruptivo que fractura la vida de las personas. Los migrantes por un conflicto armado no solo sufren la violencia y el despojo, sino que al romper todo vínculo con los referentes de lo que alguna vez fue su vida -por la acción violenta y mortal de unos seres humanos sobre otros- son lanzados a la sobrevivencia; aun cuando cuenten con el abrigo económico y jurídico de la ACNUR, sufren un despojo subjetivo y asumen la fatalidad y la carencia como elementos constitutivos de la identidad.

Ahora bien, dentro del marco de las migraciones forzadas existe una serie de determinantes que van desde los aspectos históricos, socioeconómicos, políticos, culturales, hasta los de género, étnicos, religiosos, entre otros, lo que puede ser conducente a eludir el concepto de migraciones forzadas en ponderación del sello distintivo y diferencial de cada caso específico. Si bien este ejercicio es loable e incluso indispensable para tener acceso a actores sociales, contextos, perspectivas de género, de clase, no obstante, el concepto de migración forzada tiene la función de ser un término abarcativo que reconoce el ejercicio de la violencia, la violación a los derechos humanos y la pérdida de la libertad como elementos constitutivos, lo cual permite incluir la amplia gama de especificidades en los cuales el desplazamiento es inexorable.

En otros términos, es la violencia, en tanto eje rector de las migraciones forzadas, la que permite diseccionar el fenómeno y comprenderlo en todas su variantes, y volver a articularlo bajo el término abarcativo de migraciones forzadas.

La migración forzada, de la que voy a ocuparme en este ensayo, es la migración de las comunidades indígenas mayas que se convirtieron en objetivo militar del gobierno guatemalteco en el marco de la guerra contrainsurgente. Son migraciones forzadas por conflictos bélicos que, comparativamente con otros exilios, tienen el componente étnico y cuyo estudio amerita algunas precisiones con el objetivo de ampliar el universo de estudio. 


\section{LA MIGRACIÓN FORZADA COMO EVENTO TRAUMÁTICO}

He aducido también en otro momento que las migraciones forzadas deben ser definidas no solo en razón de sus causas sino de sus efectos: Los migrantes forzados por conflictos bélicos, como las comunidades mayas de Guatemala, que son las que nos ocupan en este trabajo, no solo sufren la violencia y el despojo, sino que al ser arrancados de todo rastro de lo que alguna vez fue su vida, son lanzados a la sobrevivencia, quedan despojados subjetivamente y anulados en sus respuestas básicas para hacer frente a la adversidad y políticamente inválidos, (Cárdenas, 2011:170) en razón de la configuración de una identidad estigmatizada.

Al reconocer la violencia política como la impronta ineludible de las migraciones forzadas, indefectiblemente obliga a circunscribir el análisis en términos del binomio victimario víctima. El programa "Tierra Arrasada", como política de Estado contra la sociedad civil en Guatemala, y concretamente sobre las comunidades mayas del norte del Ixcan que cruzaron la frontera huyendo de la feroz persecución del Ejército guatemalteco, permite identificar al Estado guatemalteco, como el gran victimario, que implementó una política de terrorismo de Estado, utilizando toda una maquinaria de guerra contra una población indefensa que solo tuvo la huida como único recurso para salvar la vida. En tanto que la sociedad civil fue la víctima de este escenario sociopolítico. Este marco histórico contextual ha sido ampliamente documentado ${ }^{8}$, y por limitaciones expositivas, no voy a referirme en este acápite. Me interesa presentar algunas aproximaciones sobre el despojo subjetivo como saldo de la violencia en las migraciones forzadas.

La violencia, en términos generales, indica el uso de la fuerza objetiva o como amenaza, construida socioculturalmente, situada en un tiempo y espacio específicos, con el objetivo expreso de causar daño físico o psicológico (OMS:2003). En este artículo, desde una perspectiva holística y transdisciplinar, asumo que todas las violencias, en sus diferentes contextos y modalidades, hacen referencia a relaciones de poder y relaciones políticas necesariamente asimétricas, y esto es particularmente notable en el caso de las migraciones por conflictos bélicos. La violencia hace alusión al uso o amenaza de la fuerza física, no solamente al uso de las armas, la tortura, violaciones, asesinatos, masacres o desapariciones que reporta el amplio abanico decretado como violencia física, sino también a la violencia simbólica, entendida en los términos de Bourdieu, "como (...) aquélla que se ejerce a través de la acción del conocimiento y el desconocimiento, conocimiento y sentimiento, $(\ldots)^{9}$. Este tipo de violencia opera en el plano

\footnotetext{
7. Ibíd.

8. Véase Guatemala nunca más. El entorno histórico, Tomos I y III, publicado por la Oficina de Derechos Humanos del Arzobispado de Guatemala, 1998, Guatemala.

9. Ferrándiz Martín, Francisco y Feixa Pampols, Carles (2004) Una mirada antropológica sobre las violencias, Revista Alteridades, enero-julio, año/Vol.14, número 027, Universidad Autónoma Metropolitana, México, pp.159-172
} 
de la subjetividad y tiene como saldo la internalización de las humillaciones y la legitimación de desigualdad y jerarquía, partiendo del racismo, el sexismo y la clase, es decir, los individuos, por efecto de esta violencia, experimentan un despojo subjetivo, un vaciamiento de certeza y quebrantamiento de la voluntad; un estado anestésico que los neutraliza para posicionarse críticamente sobre los hechos, la realidad y su circunstancias y, en el peor de los casos, de facto asume su condición de marginalidad, como sino fatal.

El cartel del Ejército guatemalteco en el Petén, que a la letra reza: "Al enemigo no es destruido en la batalla, le ganas destruyendo su mente, su inteligencia y su esperanza". La violencia en el plano simbólico, como estrategia de guerra, es una violencia perversa ${ }^{10}$, que construye el enemigo despojado de toda humanidad y, por lo tanto, sin posibilidad de interlocución; responde a un plan calculado que se edifica, destruyendo y/o manipulando la normatividad, los marcos de la legalidad y el andamiaje de certezas, los puntos de referencia en los que está anclado el sentido común y el esquema de valores que hacen posible la negociación, el diálogo, el respeto o la tolerancia. Tiene como objetivo principal "desactivar" subjetivamente al otro, a través de la implementación del miedo, la persecución, de la intrusión en el territorio psicológico del otro; acosarlo sin compasión, avergonzarlo, humillarlo, rebajarlo, denigrarlo, perderle el respeto $y$, sobre todo, negar su sufrimiento ${ }^{11}$. Un acto devastador que paraliza a la víctima, al punto que esta renuncia a sus derechos, a defenderse por cualquier vía y solo reconoce la huida y el traslado súbito como única alternativa de salvación. En este sentido, la migración forzada por conflictos bélicos es un acto de absoluta sobrevivencia.

Ese tipo de violencia no solamente está referenciada durante el conflicto, sino que tiene el gravamen de perpetuarse posteriormente, pues se inscribe dentro del diagrama vital e identitario de las víctimas. Todos los entrevistados reconocen con el tiempo que debieron haberse quedado, que pudieron haber combatido, defender sus tierras y reclamar sus derechos; sin embargo, advierten fatalmente que, de haberse quedado, en realidad hubieran muerto. Todos tienen una memoria indeleble $\mathrm{e}^{12}$ de los horrores padecidos durante las incursiones del Ejército, las matanzas y masacres; el abandono de la tierra, los animales, las pertenencias, las casas ardiendo, la estampida, la urgencia, el miedo; pero también el asedio durante los viajes circulares, en un diámetro tan reducido que debieron convertirse en sombras para no ser descubiertos; sin comida, sin sal, solo empujados por la tenacidad y el sempiterno deseo de vivir. Después de 26 años, Daniel Figueroa todavía declara consternado: "cómo recuerdo eso,

10. Véase Hirigoyen, Marie-France (1999). El acoso moral, el maltrato psicológico en la vida cotidiana, Paidós, Barcelona.

11. Negar el sufrimiento es un arma política utilizada sobre todo en los casos de terrorismo de Estado, como el que nos ocupa en este trabajo; reconocerla significa la legitimidad de los otros de exigir justicia.

12. Para una aproximación detallada del fenómeno véase Cárdenas Méndez Eliana (2011) Esos históricos "Esos históricos infatigables: dinámicas migratorias de guatemaltecos en el estado de Quintana Roo 1984-2009", Capítulo I Polifonía de la Memoria. Editorial Plaza y Valdés, México. 
icómo sufríamos! iAy Dios! Recuerdo cómo sufríamos, Dios, cómo sufríamos"; entre tanto, el entramado de la guerra, entre la guerrilla y el Ejército, sigue siendo un enigma, sobre todo para las mujeres; los hombres declaran haberlo comprendido en México.

El dolor como inscripción es lo que se repite como traumatismo en todas las historias, y en esto los migrantes forzados por conflictos bélicos se diferencian de los exiliados -dicho sea de paso, otra forma de las migraciones forzadas-. Estos últimos, en una conciencia plena de las circunstancias históricas del país y la conciencia de vulnerabilidad, inician la migración forzada en el lugar de origen, pidiendo asilo en una embajada. El posicionamiento político es motor de la construcción de la identidad y resistencia de un exiliado en la comunidad receptora; para estos efectos los exiliados movilizan redes formales e informales, vínculos familiares y sociales de diferentes procedencias que, aunadas a la causa con el fin de alcanzar objetivos políticos, denuncian aislamiento de los regímenes que dieron lugar al exilio, solidaridad y recaudación de fondos, militancia activa y recuperación de ciudadanía (Coraza de los Santos, 2008:101) ${ }^{13}$.

Las migraciones forzadas de los grupos étnicos mayas de Guatemala lograron salvar la vida debido al conocimiento previo de la zona sur de México, concretamente del Estado de Chiapas, y a relaciones establecidas con hacendados cafetaleros principalmente; estas relaciones se habían amasado como consecuencia de la necesidad de mano de obra para las faenas agrícolas de las haciendas chiapanecas, de suerte que los indígenas guatemaltecos tenían una larga experiencia en la migración estacional o pendular que les había permitido conocimiento geográfico, contactos y relaciones, de manera que en el momento de la guerra les permitió obtener abrigo, asistencia y albergue mucho antes de que fueran reconocidos por la Comisión Mexicana de Ayuda a Refugiados COMAR o la oficina del Alto Comisionado de las Naciones Unidas para los Refugiados ACNUR. Sin embargo, esas relaciones no transitaron hacia causa política alguna; en principio porque los migrantes forzados solo tenían la reivindicación fundamental de salvar la vida; no tenían ningún proyecto político y, de hecho, tanto la ACNUR como la COMAR, al servir como mediadores en el conflicto con el gobierno guatemalteco, neutralizaban de alguna manera cualquier reivindicación en este sentido. Es claro, en la perspectiva de Posada ${ }^{14}$, que la categoría de refugiado es una designación jurídica para controlar las migraciones indeseadas, es decir, las motivadas por causas políticas o en el marco de un conflicto armado que, si bien les brinda una protección parcial, por otro lado impone restricciones como sujetos que reciben un trato de no ciudadanos y esto tiene profundas resonancias políticas.

Esta suerte de invalidez política se perpetuó en los Estados de Campeche y Quintana Roo, esto es claro en el reclamo petitorio y en el momento de la repatriación solo tenía dos puntos: El

13. Véase Coraza de los Santos, Enrique (2008) Redes: España y Uruguay, espacios de exilio en: Tiempos de Exilios, Memoria e Historia de españoles y uruguayos, Coord. Silvia Dutrénit Bielous, Eugenia Allier Montaño, Enrique Coraza de los Santos, Fundación Carolina, Instituto Mora, México, pp. 99-158.

14. Posada Paola Andrea. Ídem. 
retorno con garantías a su integridad física y poder recuperar la tierra; los que se quedaron y se convirtieron en ciudadanos mexicanos, les fueron retirados los auxilios y apoyos económicos internacionales y fueron lanzados a la sobrevivencia; en su calidad de naturalizados asumieron el destino de los campesinos mexicanos de migrar a los polos turísticos del Estado; así mismo, el débil tejido comunitario se ha ido fragmentando: han pasado de ser cooperativas para ser socios de proyectos de riego y frutas. Su participación política en México se circunscribe al sufragio en tiempos electorales presidenciales. Del país de origen solo les queda el recuerdo y la repetición sin fin del tiempo de la guerra, en otras palabras, el traumatismo.

\section{TRAUMATISMO, EFECTOS DE LA VIOLENCIA INTERNATILIZADA}

Desde el campo de la psicología en general, el trauma es considerado como un fenómeno agudo, un episodio ocurrido en un segmento de la historia de personas o comunidades que produce un colapso psíquico debido a que la mente se ve desbordada por la intensidad del estímulo que lo desencadena; sin embargo, el trauma no necesariamente debe constreñirse a un hecho aislado y único, sino a situaciones que pueden extenderse a periodos más o menos largos, como el caso de las migraciones forzadas. Para León y Rebeca Grinberg, la migración "en cuanto experiencia traumática podría entrar en la categoría de los así llamados traumas "acumulativos" y de "tensión" con reacciones no siempre ruidosas y aparentes, pero de efectos profundos y duraderos" $(1996: 24)^{15}$. Esta postura analítica frente al trauma y la migración permite comprender la migración forzada no solo en la dimensión del traumatismo agudo, denominado también shock trauma, sino que permite avizorar el tema del trauma en un eje temporal no solo como sumatoria de eventos acaecidos previamente, sino las resonancias que deja la experiencia misma de la guerra, de la violencia de Estado, y el sufrimiento se convierte en una especie de capital heredado y asumido que se trasmuda en una violencia internalizada al punto de que las personas renuncian al uso de la ley para reivindicarse y exigir justicia; se culpabilizan y asumen la vida y todos los eventos adversos como fatalidad de la cual es imposible escapar; el trauma es como un evento disruptivo que fractura la vida de las personas o colectivos y a partir del cual pierden cualquier posibilidad de individuación o pensamiento propio.

En términos subjetivos hemos reconocido cuadros psicosomáticos que podrían ser identificados en la taxonomía psicoanalítica como resultado del evento traumático de la migración forzada, sobre todo en las mujeres con enfermedades crónicas: -cistitis, diarreas, asma o afecciones del aparato respiratorio-, depresión, angustia o estados melancólicos. A través de entrevistas abiertas el relato de estos diversos estados conduce inevitablemente al momento de la guerra, "todo esto me viene de cuando llegó la guerra allá en Guatemala". Entre las mujeres migrantes, hijas de exrefugiados que vivieron la guerra siendo niñas, es posible reconocer vigor y valentía

15. Grinberg, León y Grinberg, Rebeca (1996). Migración y exilio, Estudio Psicoanalítico, Biblioteca Nueva, Madrid. 
en la decisión de migrar dentro del territorio mexicano; lo hicieron solas y, en el mejor de los casos, en grupos de dos o tres amigas, sin redes para la inserción laboral, con una información muy precaria sobre espacios de trabajo, con un conocimiento mínimo del castellano; durmiendo en parques, en estaciones y pidiendo trabajo de casa en casa. Al final lograron insertarse como empleadas domésticas y todas reportan discriminación, abusos y humillaciones, sin garantías laborales; las mujeres entrevistadas tienen entre 35 y 40 años y han vivido la experiencia del hacinamiento y el peregrinar en cuartos y vecindades; actualmente viven en condiciones de precariedad en las zonas marginales de Cancún, conocidas como "regiones" donde han conseguido un terreno y han edificado casas de cartón, lámina y madera; viven solas o con parejas ocasionales; la conquista del espacio ha implicado en todos los casos el cruce de las fronteras vitales, todas se han embarazado tempranamente y posteriormente han procreado hijos de diferentes parejas; han transitado por la prostitución, violencia intrafamiliar y de pareja; han vivido, incluso, la experiencia del alcoholismo y la depresión, lo cual daría por sí mismo para un estudio interdisciplinario para identificar los efectos del traumatismo en las biografías.

Sin embargo, el objetivo nuestro es reconocer el evento, los efectos de la migración forzada por un conflicto bélico en su condición de evento traumático, como se revela en tanto saldo para la comunidad en términos políticos y sociales principalmente.

Las circunstancias de extrema vulnerabilidad en las cuales llegaron los 500 mil refugiados a Chiapas y las condiciones del posterior traslado a los estados de Campeche y Quintana Roo señalan a los miembros de las comunidades mayas sin ningún margen de elección, de decisión, en el primer caso perseguidos y acosados por la campaña genocida-etnocida ${ }^{16}$ del régimen de Guatemala y después atrapados en el embrollo jurídico de México que, a fin de evitar un conflicto bilateral y con temor de un desbordamiento del conflicto armado hacia el territorio nacional, y ante las presiones de la comunidad internacional, decide reubicarlos hacia un territorio que históricamente ha estado marcado por la trashumancia, la colonización dirigida y la migración. Esta impronta se ve como traumatismo acumulativo que habrá de replicarse en conductas colectivas de auto confinamiento en términos políticos, marginalidad, exclusión, social y política y espacial entre los exrefugiados guatemaltecos.

Las tareas de asistencia por parte de la COMAR y la ACNUR permitieron a los refugiados salvar la vida, reorganizarse, construir pequeñas aldeas con escuelas, asistencia médica y adelantar

16. Véase Clastres, Pierre (1996). Sobre etnocidio, en Investigaciones sobre Antropología Política, Gedisa, Barcelona. Entiendo en este texto por genocidio, siguiendo a P. Clastres, aquel asesinato que remite a la idea de raza y a la voluntad de exterminar un grupo por sus características raciales. Sin embargo, también estos grupos han sido víctimas de etnocidio, que apunta directamente al exterminio de la cultura. El crimen genocida es un embate físico, ataca el cuerpo; en tanto el etnocidio, según el autor, dirige su ataque contra el espíritu de la cultura, es decir, destrucción sistemática de los modos de vida, representación y construcción del mundo. Los grupos étnicos a los que nos referimos en este trabajo han sido víctimas simultáneamente de estos dos tipos de criminalidad por parte del Estado guatemalteco. 
proyectos económicos para el autoconsumo y la comercialización; por otro lado, ejercía un control férreo sobre cualquier actividad que pudiera ser considerada perpetuadora del conflicto político; este tipo de restricciones, sumadas a las distancias y la falta de comunicación, no permitieron por otro lado que los refugiados entraran en contacto con organizaciones de resistencia en Guatemala ni sostener redes sociales de cooperación o colaboración, no solo en el ámbito político, sino que también ocasionó la fractura de los vínculos de relaciones básicas como las familiares.

La repatriación abrió una brecha y dividió a los exrefugiados; los que se marcharon vendieron las cosechas, cedieron o negociaron derechos sobre la participación en proyectos comunales y se lanzaron esperanzados y sin ningún proyecto ni postura política al margen de que se les garantizara la vida y se les restituyera la tierra. En la práctica, y esto también está ampliamente documentado, no solo no recuperaron todo lo perdido en el naufragio de la guerra, sino que sufrieron ataques y muchos perdieron la vida; adicionalmente debieron cargar con el estigma de refugiados que, a la sazón de las condiciones políticas y después de una enorme campaña de manipulación ideológica por parte del gobierno, significaba que en efecto habían participado en el movimiento armado, habían sido guerrilleros.

Los que se quedaron y eligieron la naturalización vivieron de nueva cuenta la experiencia de la fractura de la vida social a causa del retorno, habían perdido tejido social, fuerza y experiencia organizativa y mano de obra para fortalecer los diferentes proyectos económicos, agrícolas, de producción de abejas, cerdos, aves, etc. En estas circunstancias la migración pendular o circular, entre las comunidades y los polos turísticos de Cancún y Playa del Carmen, se convirtió en una manera frecuente de sostenimiento económico.

El retorno de los retornados, es decir, aquellos que desencantados por las circunstancias del retorno a Guatemala emprendieron camino de regreso ya no encontraron solidaridad entre los que se naturalizaron y prosiguieron un peregrinar hacia diferentes puntos de la federación mexicana y una minoría cruzó la frontera con los Estados Unidos, atomizado, sin redes sociales.

Guatemala sigue siendo una especie de paraíso perdido, mitificado con el transcurrir del tiempo, pero los vínculos con el país se mantienen a través de esporádicos viajes de visita a familiares; la comunicación incipiente, sobre todo en Guatemala, no permite la reactivación de los vínculos o las relaciones y menos de injerencia o participación política en el país centroamericano.

En México, como la gran mayoría de las comunidades indígenas, campesinas y de pescadores, completan su sustento acogidos por el programa "Oportunidades", y aunque este es un mecanismo para asegurar votos para un partido, a los exrefugiados los deja indiferentes; siempre están agradecidos por el apoyo de los mexicanos. La vida política del país tampoco es parte de sus cuestionamientos; a pesar de las diferentes coyunturas políticas que ha vivido México y que ha movilizado importantes sectores de población pidiendo un cambio o una transición hacia un régimen más democrático, los nuevos mexicanos, salvo notabilísimas excepciones entre los más jóvenes, tienen una participación política tangencial y siempre dentro de una 
estructura clientelar. En lo fundamental mantienen una relación de dependencia sin ningún posicionamiento de gestión por derechos sociales.

La segregación y el autoconfinamiento se revela en esta generación que vivió la experiencia de la migración forzada, en principio porque se mantiene su identidad étnica y no se reconocen como mexicanos, el nosotros se revela por oposición a los otros, los hermanos mexicanos; el fantasma de la repatriación, el retorno o la deportación aparece como amenaza infundada cuando se trata de dirimir conflictos de orden social en las comunidades. Durante mi permanencia en el trabajo del campo, asistí en diversas oportunidades a las asambleas donde los padres tenían que rendir cuentas a la comunidad por temas como drogadicción de los hijos; muchos de aquellos padres de familia, ante estos hechos insoslayables $y$, por lo tanto, con el gravamen "haberle fallado a la comunidad", respondieron: ni modo, no hemos cumplido como padres, y si ya nos van a deportar, ni modo. Este tipo de declaraciones es frecuente; nadie se cuestiona la invalidez de este argumento porque son ciudadanos mexicanos y ninguna autoridad puede expulsarlos del país, ni por ese problema ni por ningún otro. Pero en la base de todo este argumento está el hecho de que no se consideran sujetos de derecho.

El único puntal que da cuenta de un trabajo organizativo comunitario es la producción agrícola que las mujeres comercializan en el mercado Lázaro Cárdenas de la ciudad de Chetumal.

\section{SOMOS INDÍGENAS Y SOMOS GUATEMALTECOS, PERO MÁS APARTE SOMOS REFUGIADOS}

En medio de los puestos de frutas, verduras, carne, zapatos, ropa y mil chucherías más, el transeúnte puede indagar dónde están los puestos de verduras de las guatemaltecas; es frecuente escuchar, después de varias precisiones espaciales: allí las encuentran, ahí las va a ver usted, están todos amontonados. Son los otros, sin lugar a dudas, en el mercado Lázaro Cárdenas de la ciudad de Chetumal. Ocupan una parte del andén, en rango de 12 metros en la parte lateral del mercado y, en efecto, allí las encuentran, pero en modo alguno están revueltas, los espacios están rigurosamente delimitados por líneas imaginarias, pero efectivas, en su orden están los grupos de vendedoras de Mayabalam, Kuchumatán y San Isidro La Laguna, cada grupo de vendedoras de las tres comunidades tiene a su disposición 4 metros. Cada comunidad es dueña en la actualidad de un autobús que las transporta diariamente, en un viaje circular de la comunidad a Chetumal. En la disposición de los puestos no hay grandes distintivos, todas se cubren del inclemente sol con sombrillas o plásticos; los muebles en los que disponen los productos agrícolas son de madera o cartón. Hablan diferentes lenguas; el Kanjobal o el Mam son las más frecuentes, pero cada grupo en su lugar. En los autobuses es posible apreciar diferencias notables, que decididamente son de orden económico. El de Mayabalam es el más nuevo, y el de San Isidro es el más viejo, en tanto que el de Kuchumatán está en una situación intermedia; en esta posesión colectiva se reflejan, entre ellos, los indicadores de la economía del lugar; para los mexicanos, "todas son guatemaltecas, y allí están revueltas". 
Sigo sosteniendo que las diferentes comunidades étnicas que habitaban el Ixkán guatemalteco en las postrimerías de los años 70 no tenían una identidad nacional. La dimensión del nosotros o los otros tenía como rasero las diferencias étnica y geográfica, pero el proyecto de construcción de la identidad guatemalteca entre las diferentes etnias mayas ${ }^{17}$ se consolidó por exclusión y en el exilio en una dinámica que se expresa en tres registros: a) guatemaltecos fue la designación indistinta que recibieron de los mexicanos (con los que interactuaron por razones laborales o de los comisionados de COMAR y ACNUR) en una relación de otredad, condición de toda elaboración identitaria. b)El aprendizaje del castellano. Para estos grupos, se convirtió en una necesidad de primer orden la comunicación, y esta lengua era idónea porque era la lengua del país receptor y la lengua que hablaban mestizos y profesores rurales pertenecientes a diferentes grupos étnicos. c) La educación: el principal objetivo de la COMAR y de la ACNUR fue la construcción de escuelas y las campañas de alfabetización que permitieron a los exrefugiados conocer la historia oficial del país de procedencia, la representación de ese territorio nacional a través de mapas que fue forjando un sentido de pertenencia a esa comunidad imaginada que es la nación. e) La comunidad afectiva surgida por la experiencia de la travesía para salvar la vida, los lazos de solidaridad y, a la postre, la voluntad de vivir juntos en el territorio designado por las autoridades mexicanas.

El proceso de repatriación propició el retorno de más del 50\% de los refugiados de las comunidades de Campeche y Quintana Roo. Los que decidieron quedarse en México iniciaron posteriormente el proceso de naturalización y adquirieron la nacionalidad mexicana.

Para la primera generación de refugiados que albergan en las comunidades de Mayabalam, Kuchumatán y San Isidro La Laguna, que optaron por la nacionalidad, se produjo una especie de fragmentación de la identidad, una especie de espejo roto, que recibió diferentes adscripciones: indígenas, guatemaltecos, refugiados y mexicanos. Esta última opera de manera instrumental en esta generación, jamás se han sentido mexicanos y todos viven en la convicción de estar en una tierra que no les pertenece: "ni modo, vivimos en una tierra ajena, qué le vamos a hacer, somos guatemaltecos, ni modo"18. Las demás son identidades que comportan estigma.

La guerra dirigida contra las comunidades indígenas tenía el componente histórico de la discriminación racial por parte de una minoría blanca o mestiza. La idea misma de la nación o del Estado nacional o soberanía nacional se ha fraguado históricamente con la plataforma de una etnia nacional: "Ninguna nación moderna, por más benigna que sea su sistema político, por más elocuente que sean sus voces públicas respecto a las virtudes de la tolerancia, el

17. Para definir la composición étnica que llegó al Estado de Chiapas fue preciso recurrir a la filiación lingüística. Según una estimación realizada en 1984 establecía que la población mestiza ladina constituía el 20\%, mientras que el resto formaba parte de alguno de los siguientes grupos indígenas: Kanjobal 27\%, Mam 24\%, Quiché 9\%, Cluj 8\%, Jacalteco7\%, Kekchi 2\% y Chol 0.2\%, Véase: Nolasco y Melasio 1986.

18. Notas de campo, hablantes de Mam, Kanjobal, Mayabalam y Kuchumatán 2009. 
multiculturalismo y la inclusión, está libre de la idea de que su soberanía se halla construida sobre una suerte de genio étnico" (Apaddurai, 2007:16) ${ }^{19}$.

Los indígenas son los excluidos del gran discurso identitatio de la nación guatemalteca; de hecho, se ha erigido en franco rechazo a las poblaciones autóctonas; a diferencia de países como México, con altas tasas demográficas de población de origen prehispánico, se construyó una idea de nación mestiza, mezcla de blanco e indio, un discurso ideológico que tenía puentes entre dos grupos enfrentados a lo largo de los diferentes momentos de la historia del país. La educación fue el instrumento de este proceso de aculturación. Guatemala, por oposición, no alentó esfuerzo alguno por incorporar a los indígenas como integrantes del calidoscopio cultural, muy por el contrario, en este país se alentó un discurso discriminatorio, que se cristalizó en una campaña de odio que combinaba intereses de clase hacia la guerrilla, pero con tintes de limpieza étnica contra las comunidades mayas del Ixkán; el argumento oficial declara que los indígenas guatemaltecos servían de base social a la guerrilla del EGP ${ }^{20}$, sin embargo, aunque algunos se declaran simpatizantes del movimiento armado, la gran mayoría de los indígenas mayas, se declaran ignorantes del proyecto político del EGP, que buscaba adeptos afanosamente en estas comunidades a fin de subsanar una de las grandes contradicciones que identificaban como causa de los desajustes sociales del país incorporándolos a la lucha armada y resolver, a juicio de sus líderes, la contradicción clasista. Esta propuesta, sin embargo, no ganó grandes adhesiones entre este grupo de campesinos más afines al comunismo religioso del padre Guillermo Woods ${ }^{21}$, que a la lucha ideológica de clase contra el estado burgués capitalista.

La identidad étnica como un elemento de discriminación con una larga data de marginación, pobreza y exclusión se refrendó, por efecto de la guerra y la migración, como una identidad estigmatizada; el estatuto de refugiado fue una de las piezas de ese rompecabezas identitario asumido en el exilio; si bien para los que se quedaron se convirtió en una designación jurídica que daba protección, al mismo tiempo era arma política por la defensa de sus derechos; sin embargo, para los retornados de $1999^{22}$ fue una categoría estigmatizadora que los refrendaba

19. Appadurai, Arjun (2007). El rechazo de las minorías, ensayo sobre la geografía de la furia, TusQuets editores, España.

20. EGP Ejército Guerrillero de los Pobres, la organización guerrillera con mayor número de militantes y mayor control territorial en Guatemala.

21. El sacerdote norteamericano, Guillermo Woods fue fundador de la Cooperativa Malin en Santa Cruz Barillas, colonizador del Ixkán Playa Grande en compañía de 2 mil familias y reunificador de la Aldea Palestina La Unión, con el propósito de adelantar proyectos de autogestión agrícolas y ganaderos, entre las comunidades mayas. La muerte del padre Woods, el 20 de noviembre de 1976, en un extraño accidente aéreo nunca esclarecido, marcó el comienzo de las violaciones de los derechos humanos y el inicio de las masacres en el Ixkán que desembocó en la migración forzada de las comunidades mayas hacia México.

22. El 28 de julio de 1999, en Champotón, Campeche, tuvo lugar una ceremonia simbólica de la Conclusión del Refugio Guatemalteco en los Estados de Campeche y Quintana Roo. Ese día se entregaron cartas de naturalización a 939 personas, para un gran total de 2.740, expedidas a esa fecha, luego de cuatro años, en el marco del Programa de Estabilización Migratoria. 
como guerrilleros y revitalizó nuevas persecuciones; ser guatemalteco en el sur implica una suerte de nacionalidad estigmatizada que convierte a los portadores en objeto de discriminación por parte de las autoridades y de la población en general. En este contexto ser mexicano es una autoadscripción que permite instrumentalizar y negociar en el juego de intereses de los escenarios sociopolíticos y culturales.

\section{CONCLUSIONES}

Abordar los procesos de construcción de las identidades estigmatizadas desde la perspectiva del trauma contribuye a la comprensión de procesos represivos y la forma en la que se instala en los espacios intersubjetivos, de suerte que es posible afirmar que lo traumático nos vincula con la historia de lo acaecido y el saldo de consecuencias que deja en los colectivos e individuos como sedimentaciones y síntomas de esa historia que reconoce la violencia como eje ordenador de su narrativa.

Resulta paradójico presentar el traumatismo, de la migración forzada, como ordenador de identidades en exclusión o estigmatizadas, en la medida en que el traumatismo por definición no es estructurador y, muy por el contrario, tiene un efecto desvertebrador, debido a su carácter disruptivo y sorpresivo, de manera que irreductible a la simbolización, el hecho traumático quedará asumido como fatalidad, como algo externo que irrumpe en la vida de las personas y que oscurece y dificulta un posicionamiento crítico de la comprensión de los hechos. El traumatizado solo repite incansablemente sin encontrar los vasos comunicantes que le den un lugar en el entramado de sucesos como actor social. La incertidumbre y el asombro es la impronta constante que está al final de cada evocación de lo ocurrido.

En ese sentido, encontramos personas y colectivos emplazados en un presente perpetuo, sin poder tramitar psíquicamente la historia y la memoria del pasado; es por esto que, si bien el traumatismo es desestructurante, puede reconocerse por otro lado el carácter fundante que tiene el despojo subjetivo.

La consulta en entrevistas a los exrefugiados, durante dos años de trabajo de campo, acerca de la guerra y la migración forzada evoca con detalles los bombardeos, las vicisitudes, los imponderables, la vida, la muerte, la pérdida, las argucias contra el enemigo, la huida y las estrategias de sobrevivencia; a lo que muy pocos pueden responder es acerca de las causas, de las responsabilidades, en qué consistía el entramado de la guerra y por qué razones se convirtieron en objetivo militar. Si logran articular un discurso explicativo, después de las consabidas, "ya ni modo", "así es la maldad humana", "la guerra cae cuando menos lo esperas", es posible que se reconozcan como perdedores, confundidos; en algunos casos impotentes "ellos tenían armas y nosotros nada"; hay, sin embargo, quienes responden asumiendo el discurso de la represión: nadie puede contra los ricos, nosotros somos pobres y si trabajamos poco a poco, compras un puerco y lo vendes y con ese dinerito consigues otro puerco y así poco a poco consigues lo 
tuyo; los ricos así lo hicieron y por eso tienen su dinero, ni modo que vayas a quitarles a ellos, tienen que defenderse y así lo hicieron"; "algunos sí se dejaron convencer de la guerrilla y se fueron con ellos, pero la guerrilla los engañó porque no se le puede ganar al gobierno"23.

Las migraciones forzadas por conflictos bélicos refieren fenómenos que desarticulan las relaciones sociales, los códigos de interacción y convierten el miedo en el sostén de las relaciones con los "otros" y obliga a poner a prueba la estabilidad personal.

El traumatismo de la migración forzada, donde quiera que se presente, es un caso de justicia sin resolver, no solo como hecho acaecido, sino por las resonancias que ha dejado en las personas que vivenciaron el hecho y por las repercusiones que se han transmitido transgeneracionalmente. El traumatismo, como evento disruptivo, tiene un saldo de consecuencias en el entramado de las relaciones sociales de un colectivo, como el de Mayabalam, Quintana Roo, que se revela en el autoconfinamiento, internalización de la fatalidad como destino ineluctable que asume el fracaso como impronta en la interacción con los demás y descubre individuos inhabilitados para una plena aceptación social.

En este sentido, es preciso insistir que el trauma es inscripción, congelamiento del tiempo y del espacio, por lo tanto, el relato de lo acaecido como acto catártico no es redentor o garantía de liberación por sí mismo, cada evocación actualiza el evento traumático cuya liquidación fracasa en la medida en que se queda como herida, pues no deviene en interpretación que significa siempre la recuperación del sujeto; los migrantes forzados repiten el episodio una y otra vez, y estarán condenados a ello en tanto no logre elaborarse y convertirse en memoria histórica donde lo que se recupera es el contexto que es lo que produce significación (Cardenas:2011:266). Solo de esta manera se hace el tránsito de esta construcción del indígena refugiado, asistido y pasivo a una reconceptualización del refugiado como sujeto histórico.

\section{REFERENCIAS}

- Appadurai, Arjoun (2010). El rechazo de las minorías, ensayo sobre la geografía de la furia, TusQuets editores, España.

- Bourgois, P (2001). "The continuum of violence in war and pieace, Post-cold war lessons from El Salvador en Ethnography, Vol. 2, num. 1 pp. 5-34

- Cárdenas Méndez, E. (2011). Esos históricos infatigables, dinámicas migratorias de guatemaltecos en el Estado de Quintana Roo 1984-2009, Editorial Plaza y Valdés, Madrid, España.

23. Hablantes de Mam y Kanjobal, notas de campo, Mayabalam, 2008. 
- Coraza de los Santos, E. y otros (2008). "Tiempos de exilio. Memoria de historias de españoles y uruguayos", Instituto Mora, Fundación Carolina.

- Clastres, P. (1996). "Sobre etnocidio" en Investigaciones sobre Antropología Política, Gedisa, Barcelona.

- Ferrándiz Martín, F. y Feixa Pampols, C. (2004). Una mirada antropológica sobre las violencias, Revista Alteridades, enero-julio, año/Vol.14, número 027, Universidad Autónoma Metropolitana, México.

- Oficina de Derechos Humanos del Arzobispado de Guatemala (1998). Guatemala nunca más, El entorno histórico, Tomos I y III

- Grinberg, León y Grinberg, Rebeca (1996). Migración y Exilio, Estudio Psicoanalítico, Biblioteca Nueva, Madrid.

- Hirigoyen, M-F. (1999). El acoso moral, el maltrato psicológico en la vida cotidiana, Paidós, Barcelona.

- Kufman, S. G. "Sobre violencia social, trauma y memoria" www.cholonautas.edu.pe/ modulo/upload/GKauffman.pdf.

- Nolasco M. y Melasio M. (1986). "Principales grupos étnicos indígenas y ladinos" en Los Refugiados Guatemaltecos, Fondo de Cultura Económica, México.

- Posada, P. A. (2009). "Refugiados desplazados forzados. Categorías de la migración forzada creadas como medidas de contención a las migraciones no deseadas", Estudios Políticos No. 35, Medellín, julio-diciembre, pp. 131, 152.

- Turqui, J. E. (2006). Trabajadores indígenas en la ciudad de Guatemala y el movimiento maya, Explorando la representación de demandas étnicas y laborales. Instituto de Estudios Interétnicos, Universidad de San Carlos, Ciudad de Guatemala.

- Uva Falla Ramírez, Yuria Chavas Plazas, Gladys Molano Beltrán (2003). “Desplazamiento forzado en Colombia", Tabla rasa, Bogotá Colombia, No. 1: 221-236, enero-diciembre. 